\title{
PERSPECTIVE
}

\section{Original research in pathology: judgment, or evidence-based medicine?}

James M Crawford

Pathology is both a medical specialty and an investigative scientific discipline, concerned with understanding the essential nature of human disease. Ultimately, pathology is accountable as well, as measured by the accuracy of our diagnoses and the resultant patient care outcomes. As such, we must consider the evidence base underlying our practices. Within the realm of Laboratory Medicine, extensive attention has been given to testing accuracy and precision. Critical examination of the evidence base supporting the clinical use of specific laboratory tests or technologies is a separate endeavor, to which specific attention must be given. In the case of anatomic pathology and more specifically surgical pathology, the expertise required to render a diagnosis is derived foremost from experience, both personal and literature-based. In the first instance, knowledge of the linkage between one's own diagnoses and individual patient outcomes is required, to validate the role of one's own interpretations in the clinical course of patients. Experience comes from seeing this linkage first hand, from which hopefully comes wisdom and, ultimately, good clinical judgment. In the second instance, reading the literature and learning from experts is required. Only a minority of the relevant literature is published in pathology journals to which one may subscribe. A substantial portion of major papers relevant to the practice of anatomic pathology are published in collateral clinical specialty journals devoted to specific disease areas or organs. Active effort is therefore required to seek out the literature beyond the domain of pathology journals. In examining the published literature, the essential question then becomes: Does the practice of anatomic pathology fulfill the tenets of 'evidence-based medicine' (EBM)? If the pinnacle of EBM is 'systematic review of randomized clinical trials, with or without meta-analysis', then anatomic pathology falls far short. Our published literature is largely observational in nature, with reports of case series (with or without statistical analysis) constituting the majority of our 'evidence base'. Moreover, anatomic pathology is subject to 'interobserver variation', and potentially to 'error'. Taken further, individual interpretation of tissue samples is not an objective endeavor, and it is not easy to fulfill the role of a 'gold standard'. Both for rendering of an overall interpretation, and for providing the semi-quantitative and quantitative numerical 'scores' which support evidence-based clinical treatment algorithms, the Pathologist has to exercise a high level of interpretive judgment. Nevertheless, the contribution of anatomic pathology to 'EBM' is remarkably strong. To the extent that our judgmental interpretations become data, our tissue interpretations become the arbiters of patient care management decisions. In a more global sense, we support highly successful cancer screening programs, and play critical roles in the multidisciplinary management of complex patients. The true error is for the clinical practitioners of 'EBM' to forget the contribution to the supporting evidence base of the physicians that are Anatomic Pathologists. Finally, the academic productivity of pathology faculty who operate in the clinical realm must be considered. A survey of six North American academic pathology departments reveals that $26 \%$ of all papers published in 2005 came from 'unfunded' clinical faculty. While it is likely that their academic productivity is lower than that of 'funded' research faculty, the contribution of clinical faculty to the knowledge base for the practice of modern medicine, and to the academic reputation of the department, must not be overlooked. The ability of clinical faculty in academic departments of pathology to pursue original scholarship must be supported if our specialty is to retain its preeminence as an investigative scientific discipline in the age of EBM.

Laboratory Investigation (2007) 87, 104-114. doi:10.1038/labinvest.3700511

KEYWORDS: surgical pathology; clinical scholarship; gold standard

Department of Pathology, Immunology and Laboratory Medicine, University of Florida College of Medicine, Gainesville, FL, USA

Correspondence: Dr JM Crawford, MD, PhD, Department of Pathology, Immunology and Laboratory Medicine, University of Florida College of Medicine, PO Box 100275, Gainesville, FL 32610-0275, USA. E-mail: crawford@pathology.ufl.edu

Received and accepted 16 November 2006 
'Pathology' is the medical specialty concerned with the essential nature of disease, practiced by trained physicians for the benefit of patient care. 'Pathology' also is a scientific discipline, since the very process of understanding human disease is a scientific endeavor. However, defining the 'discipline' of pathology is problematic, since investigation of human disease spans all the scientific disciplines of biomedical research. Hence, the identity of 'pathology' is evanescent. On the one hand, medical students considering pathology for post-graduate training are given little opportunity to appreciate what Pathologists actually do-it is only the fortunate few who can appreciate the extraordinarily fulfilling nature of a potential career in the specialty of pathology. On the other hand, academic departments of pathology have to be all things to all people, owing both to the need to provide outstanding diagnostic expertise for all of the practicing clinical specialties and subspecialties, and to the need to have robust research programming in some or many realms of disease pathobiology. Further, one can wonder how 'specialty' and 'discipline' knit together into the concept of pathology as a 'profession'. A profession is an occupation that requires extensive training, the study and mastery of specialized knowledge, and usually has an ethical code and process of certification or licensing. Corollaries are that one has to swear an oath to uphold the ethics of the profession, and 'profess' to a higher standard of accountability. To the extent that accountability ultimately is measured on the basis of patient outcomes, the 'profession' of pathology is subject to consideration of the evidence base underlying our practices.

From a historical perspective, what we might call 'pathology' emerged early in the practice of medicine. The technology of ancient times was straightforward, as exemplified by Hippocrates: the taking of a medical history and a bedside examination. A significant innovation in that era was examination of the urine. The dawn of rigorous medical science began with systematic dissection of the human body, beginning with Galen (129-200 AD). After a prolonged hiatus through medieval times, the Italian anatomists of the 15th century laid the groundwork for the publication in 1543 by Vesalius of the first books of morbid anatomy, De humani corporis fabrica libri septem ('The Seven Books on the Structure of the Human Body'). Robert Hooke was the first to use the word 'cell' to name the small cavities in the honeycomb, in his 1665 book Micrographia ('Small Drawings'). This work was soon followed by Malpighi's De viscerum structura exercitatio (1666), which essentially founded the fields of histology and microscopic anatomy, and Van Leeuwenhoek's remarkable advances in construction of microscopes, enabling his extensive studies of 'animalcules' (single-celled organisms) by 1675 . Giovanni Morgagni of Padua published in 1761 the great work De sedibus et causis morborum ('On the sites and Causes of Diseases'), followed ultimately by Rudolf Virchow's landmark publication in 1858 of Die Cellular-pathologie, which conceived of the cell as the center of all pathological changes. In the decades that followed, especially in Europe, the role of the Anatomic Pathologist as the final arbiter in human disease became well established.

The dawn of the 20th century saw an increasing role for the clinical laboratory in patient care world-wide, over-andabove the utilization of the microscope. By the early 1920s, physicians practicing in the clinical laboratories of the day recognized the need for elevation of this activity to full professional status, and in 1926 the American College of Surgeons revised its minimum standards for hospitals to require that 'clinical laboratories be under the direction of MD physicians with special training in clinical pathology, with all tissue removed at operations to be examined in the laboratory and reports rendered thereon.' The American Board of Pathology was instituted in 1936. Finally, in 1943 'pathology' was recognized as the 'practice of medicine' by the House of Delegates of the American Medical Association.

Yet even the great Virchow was subject to error (whether it was sampling or interpretive error is a matter of speculation). In one of the most vituperative medical quarrels between opposing treating physicians in history, ${ }^{1}$ the crown prince Frederick (1831-1888), son of William I, Emperor of Germany, fell ill with laryngeal hoarseness in January 1887. Although a laryngeal cancer was suspected from the outset, initial biopsies sent to Virchow for interpretation were either insufficient for diagnosis or interpreted as pachydermia verracosa (throat wart). Subsequent biopsies were necrotic or too purulent for diagnosis, despite overwhelming clinical evidence that the laryngeal process was malignant. Failure to obtain an anatomic diagnosis of malignancy, per Virchow, immobilized the clinical treatment team. Only when Frederick was in extremis (February 1888) did laryngeal biopsy finally reveal the 'little bodies that brought it all about' (to quote his son, the future Kaiser Wilhelm II).

Although Virchow's reputation appears to have been unharmed, this episode was illustrative of the potentially shaky status that pathology holds as the diagnostic bedrock for patient care. In this Editorial Perspective, consideration will be given to a number of pertinent issues, focusing primarily on the role of anatomic pathology. First, on what basis are diagnostic assessments made in anatomic pathology? Second, does this diagnostic exercise fulfill the requirements for EBM? Third, how well does anatomic pathology serve as a 'gold standard' for research being conducted on human tissues? Lastly, what is the academic productivity of pathology scholars who, operating in the clinical realm, are given opportunity to publish their original findings?

\section{THE BASIS OF DIAGNOSIS IN ANATOMIC PATHOLOGY}

My first encounter with the diagnostic process in surgical pathology was on my second day of residency (1982), when my confident diagnosis of 'axillary lymph nodes positive for metastatic breast carcinoma' was countermanded by the attending pathologist: I was simply observing 'sinus 
histiocytosis' in the lymph nodes. My silent indignant reaction was, 'On what basis do you know that you are right, and I am wrong?' Put differently, how can it be that morphologic examination of devitalized human tissue that has been fixed in formalin, dehydrated and permeated with paraffin, sliced thinly and stained with biblical era colorizing agents (hematoxylin \& eosin), covered in glue and sandwiched between glass, has any bearing on clinical management decisions made for the living patient? Potential answers include, 'Because I am the authority here', or 'My experience', or 'This is what I was taught', or 'This is what the recent literature indicates', or even 'This is what is required for synoptic reporting.' Then and now (24 years later), I am forced to conclude that, ultimately, it is the experience base of over a century-and-a-half of cellular Pathologists that enables us to have credibility in dictating the fortunes (and misfortunes) of living patients.

The question then immediately arises: how is this experience-base established, and what credibility does it have? In a 2006 Lab Invest editorial, ${ }^{2}$ I asked this specific question for human liver biopsy interpretation. The methodology was to examine the top 150 most-cited publications in which human liver pathology was included, either as the primary focus of the publication or as contributing data. The dates of publication for these papers were from 1948 to 2003, with a heavy representation of published papers by the most honored leaders of our subspecialty. The results were remarkable: essentially half (48\%) of the 'classics' in liver pathology were Case Series, which is the reporting of an assembled experience. Another $10 \%$ were case series that included additional research in the basic laboratory, so as to obtain insights into the molecular or structural basis of the disease. An additional $16 \%$ were 'Position Papers', either declarative by authorities in the field, reports by consensus panels, or reviews. So $\frac{3}{4}$ of the most cited papers in the liver pathology field were published predominantly on the basis of 'experience' or 'opinion'. Only $26 \%$ of these 150 most-cited papers would qualify for 'Evidence-Based Medicine (EBM)' (to be discussed). These were exclusively within the realm of viral hepatitis, in which clinical outcomes clearly established that liver biopsy was a useful diagnostic investigation in the management of patients with Hepatitis B or C viral infection.

These findings in liver pathology are echoed in a 2005 article by Foucar and Wick ${ }^{3}$ (actually published in February 2006). These authors performed a pilot observational analysis of a representative sample of the current pertinent literature on diagnostic tissue pathology. They show that most of such publications employ 'observational' research designs, most commonly 'cross-sectional comparison'. Slightly more than $50 \%$ of the anatomic pathology observational studies employed statistical evaluations to support their final conclusions. Unfortunately, such research designs are not admired by advocates of EBM, since they are a distant second choice to 'experimental' clinical studies. Foucar and Wick advocate that the latter posture is unacceptable to pathologists, whose research advances are currently completely dependent upon well-conducted observational research. Rather, the challenge to anatomic pathology is to develop and adhere to standards for observational research-including the classification of error in anatomic pathology ${ }^{4}$ - so as to realize the full potential of this time-tested approach for advancing clinical knowledge. $^{3}$

So how does one actually become a good diagnostic Surgical Pathologist? At the risk of being pedantic, I consider that, first and foremost, knowledge of the linkage between the anatomic pathology data and the patient is required: knowing the relationship between the disease process and clinical outcomes in the living patient. To this is added experience: seeing this linkage first hand. Wisdom hopefully follows: learning from experience (the cynic would observe that one is usually learning from bad experiences, with which I disagree). This requires communication, most especially validating the role of one's own histological interpretations in the clinical course of the patients one has influenced. Hopefully the final product is good clinical judgment, upon which weighs heavily the taking of responsibility for your decision-making. To be a great surgical pathologist, more extensive knowledge of the clinical presentations, course, and management of patients is required, along with authority. The first attribute (clinical knowledge) is constantly strengthened by obtaining the clinical information at the time of tissue evaluation: clinical presentation, clinical findings (including imaging characteristics), pertinent past and family history; and by constantly pursuing information about subsequent clinical course. Participation in multidisciplinary patient care conferences is a valuable way for pathologists to get feedback about clinical and therapeutic outcomes which were triggered by the histopathological interpretation of tissues. The latter attribute (authority) is gained especially by contributing new knowledge to the field of surgical pathology on the basis of one's own published scholarship.

In assembling knowledge, there is a challenge in finding the published literature-case series or otherwise. In the liver pathology field, at least, ${ }^{2}$ only $16 \%$ of the 150 most-cited papers were published in 'pathology' journals; $84 \%$ were published in 'Clinical' journals (eg, Gastroenterology, Hepatology, J Hepatology). If this is any reflection of surgical pathology in general, in order to find the most-cited published papers in surgical pathology, one has to put especial effort into reading the clinical journals of each related clinical specialty/subspecialty. One could also read textbooks, especially on a per case basis, relying upon the experience and authority of the writer. Very importantly, one can learn from local colleagues, so as to draw upon the collective expertise and experience of the local practice group. Fourth, it is worth taking opportunity to learn from 'experts', as at national meetings and at special courses. 'Reading the literature' is a given, but this is usually for the limited portfolio of journals to which one subscribes. I also recommend actively seeking out the published 'evidence base' (such as it may be) for the 
major disease categories of one's practice on a regular, proactive basis; 'Journal Club' is one such impetus for so doing. One can seek out informative websites, such as (www.uscap. org). Lastly, we can now subscribe to 'push' electronic services, which post to our computer desktop listings of newly published papers which should be of interest to us. It does take reading them.

\section{EBM IN ANATOMIC PATHOLOGY}

So we come to the essential question: is an Anatomic Pathologist rendering an 'expert' interpretation, or an 'evidence-based' interpretation. This begs the question, what is 'EBM'? A brief history is appropriate. ${ }^{5}$ In the first half of the 20th century, a fundamental premise of modern medicine was that 'Each physician will think the right thoughts and do the right thing. To quote Eddy, 'The idea was that when a physician is faced with a patient, by some fundamentally human process called the 'art of medicine' or 'clinical judgment', the physician would synthesize all of the important information about the patient, relevant research, and experiences with previous patients to determine the best course of action, ${ }^{5}$ In the published literature and in medical textbooks, medical knowledge becomes a compendium of 'if....then' statements. As further detailed by Eddy, in 1973, Wennberg and Gittelson ${ }^{6}$ documented that there were wide variations in clinical practice patterns, in the absence of apparent justification for such variations. In the 1980s, a group of physicians at the RAND Corporation changed the frame of reference entirely, by reporting that inappropriate medical procedures were being done by apparently well-informed physicians, such as the use of coronary angiography. ${ }^{7}$ This was paralleled in 1985 by a highly influential Institute of Medicine report quoting a congressional committee statement that 'only $15 \%$ of medical practices are based on clinical trial evidence. ${ }^{8}$ By the late 1980s, an increasing number of randomized clinical trials were documenting that certain current clinical practices were ineffective.

Such discussions made clear the need for more rigorous study of medical decision making, and the general concepts underlying EBM were evolving through the 1970s and 1980s. ${ }^{9}$ David Eddy in $1990^{10}$ discussed the different methods for designing clinical practice guidelines: preference-based; 'global subjective judgment'; consensus; outcomes based, and evidence based - the first published use of this term. As summarized by Akobeng in 2005, ${ }^{11}$ the 'evidence base' for the practice of clinical medicine follows a hierarchy (Figure 1), in which 'opinion', 'case reports', and 'case series' are at the bottom. Unfortunately, this is precisely where anatomical pathology seems to live. At the peak of the pyramid are the randomized clinical trails, which are assembled into 'systematic reviews of randomized clinical trials, with or without meta-analysis'. Indeed, it is the latter that find their ways into the lay press, when systematic reviews find that 'fish oil may not reduce cancer risk' or 'soy has little effect on cholesterol. ${ }^{12}$ Such lay publicity arises chiefly because the medical

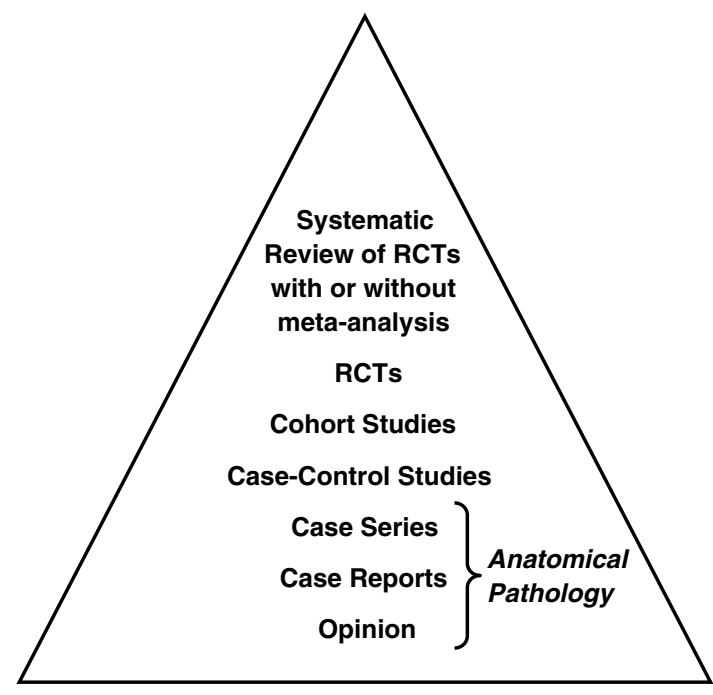

Figure 1 Hierarchy of evidence for questions about the effectiveness of an intervention or treatment. From Akobeng. ${ }^{11}$ Adapted and reproduced with permission from the BMJ publishing group. The designation of 'Anatomical Pathology' is added. RCT, randomized clinical trial.

literature has a propensity to publish positive results only, and not publish negative studies which refute exciting new clinical findings. It takes 'systematic reviews' not only to authenticate a growing body of positive clinical evidence, but also to refute nagging reports which won't go away. The Wall Street Journal noted that 'the scientific literature is biased towards positive results', and 'there is need for recognizing results which run counter to positive results.' ${ }^{13}$ Two journals gaining visibility in that regard are the Journal of Spurious Results and the Journal of Negative Results in Biomedicine.

The founding goal of EBM was to enhance the teaching of medical residents, ${ }^{5}$ especially as articulated in 1992 by the EBM Working Groups. ${ }^{14,15}$ Although it was David Eddy who introduced the term, its use was irrevocably altered by a 1996 editorial by David Sackett (Associate Editor of the British Medical Journal), who stated that EBM is 'the conscientious, explicit, and judicious use of current best evidence in making decisions about the care of individual patients. ${ }^{16}$ The practice of EBM means 'integrating individual clinical expertise with the best available external clinical evidence. The goal was to improve the quality of patient care through the identification and promotion of practices that work, and the elimination of ineffective or harmful ones. This requires clinicians to be open-minded and to try new methods that are scientifically proven to be effective, and to discard old methods that are not. The presumed benefits of EBM are: to help clinicians deal with 'information overload'; to reduce inequalities in the delivery of healthcare (and distribute healthcare resources more equitably); to help reduce healthcare costs; and to justify treatment choices to the public. Vociferous criticisms are that EBM removes the 'art' from the practice of medicine. The rejoinder (articulated by Sackett himself in numerous follow-up letters) is that external 'evidence' is always to be 
tempered with internal experience. Eddy also observes that evidence in support of the practice of EBM still needs to be developed. ${ }^{15}$

The practice of EBM would seem to presume that the practice of medicine is, in fact, a science. Arguably, 'science' is the formulation and attempted falsification of hypotheses using rigorous and reproducible methods. Applied to Medicine, 'diagnostic inquiry' is equated with 'scientific inquiry', with the premise that clinical observation is objective-including the diagnostic exercise that is anatomical pathology.

But clinical observation is not objective. As articulated by Trisha Greenhalgh, medicine is an 'art' because the 'truths' obtained from patient populations (ie, randomized controlled trials) cannot be reconciled with individual patients. ${ }^{17}$ An 'evidence base' cannot substitute for clinical judgment, since the practicing physician has to interpret the patient's 'narrative' (their clinical course) before it can be placed in the context of the published literature. She states that the search for objective truths in a patient is a flight from interpretation, and is doomed to fail. Put differently, suspension of clinical judgment is a very bad idea. Genuine evidence-based practice presupposes an interpretive paradigm in which the patient experiences illness in a unique and contextual way. It is therefore the responsibility of the treating physician to reconcile individual patient 'narratives' with the 'truths' derived from population-based evidence. This can only be achieved through the use of clinical judgment.

We now return to anatomical pathology. Although our practices may be filled with routine diagnostic events, it is almost guaranteed that, with regularity, we encounter extraordinarily unusual cases. To deal with such a case, one must: become completely familiar with the clinical narrative; review the world's literature; consult with colleagues (beginning with local colleagues, then proceeding to national authorities and even international, as needed); and then render one's interpretation, complete with prognostic implications. Remarkably, one may then have to educate the clinical treatment teams on what you have actually identified, beginning with the disease process and moving on to the implications of the pathology interpretation. This may be termed 'gaining a lifetime of experience with one case.' It is hard to call this the 'science' of medicine. Rather, the pathologist is bringing all available information to bear on this one case, including most importantly experience. Ironically, this is much like David Eddy's description of the practice of medicine in the pre-'evidence based' era. ${ }^{5}$

Specific interest in the role of EBM in pathology has only recently awoken. While Laboratory Medicine has long paid attention to testing accuracy and precision, ${ }^{18-22}$ only recently has there been critical examination of the implicit assumption that an evidence-based culture underpins the use of laboratory medicine. The results are of concern, since the evidence base supporting use of a specific laboratory test procedure or technology in specific clinical situations may be quite limited or flawed. ${ }^{23,24}$ Indeed, the failure to demon- strate the effective utilization of laboratory tests generated either in the clinical laboratory or in anatomic pathology puts the profession of pathology at risk of being deemed outside 'best practices', and hence ineligible for reimbursement. ${ }^{25}$ It is hoped that there will be continued effort to advance 'evidence-based laboratory medicine. ${ }^{26}$

In the case of anatomic pathology, in 1996 Baker et $a l^{27}$ analyzed anatomic pathology databases to assess autopsy performance. The 2001 'consensus guidelines for the management of women with cervical cytological abnormalities ${ }^{28}$ constitutes a tour-de-force analysis of the evidence base in support of cervical cytology examination and validated clinical outcomes. Nevertheless, in 2000 Sirota made clear that the 1999 Institute of Medicine report on 'medical error' should be applied to the practice of pathology. ${ }^{29}$ Marchevsky and Wick ${ }^{30}$ are the first to examine the broader role of EBM and 'medical decision analysis' (whereby mathematical tools are used to 'reason with uncertainty') in the practice of pathology. They noted that pathologists will be well served by becoming more familiar with the basic concepts of EBM and how pathology data can be better integrated into formal medical decision analysis.

The message evidently has been heard. Beginning with Zarbo and coworkers, ${ }^{31-34}$ the role of error in the practice of anatomic pathology on patient management and clinical outcomes is now being rigorously examined. The entire May 2005 issue of Seminars in Diagnostic Pathology was devoted to the role of EBM in pathology. ${ }^{3,4,25,35-39}$ A key point of these articles is that the practice guidelines of surgical pathologists, including our most revered classification schemes, are generally based on 'expert opinion', representing the weakest form of evidence. ${ }^{39}$

\section{ANATOMIC PATHOLOGY AS A 'GOLD STANDARD'}

At what point does a Pathologist's 'interpretation' become a datum, to be used as a 'gold standard' in the practice of medicine? At the very least, the difficulties in reproducibility of histological and cytological diagnoses due to interobserver variation' challenge the concept of anatomic pathology as a gold standard. ${ }^{40-43}$ In September 2004, I examined the PubMed citation index for the term 'interobserver variation'. Subcategories were '...AND pathology', 'AND cancer', and 'AND pathology AND cancer'. In October 2006, I repeated this exercise (Figure 2). In each search, the number of citations increased by 33 to $37 \%$. In other words, the indexed world's biomedical literature in 'interobserver variation' increased by $1 / 3$ between late 2004 and late 2006! Clearly, we have a problem. Among observers of the practice of pathology, we are viewed not as a 'gold standard' but rather as a 'brass standard', or a 'tin standard'.

A second issue arises from the practice of algorithmic EBM, in which semiquantitative or quantitative scores from anatomic pathology diagnoses are used to determine treatment interventions-pharmaceutical or surgical. In my experience (there we go), if the Treating Physician is making 


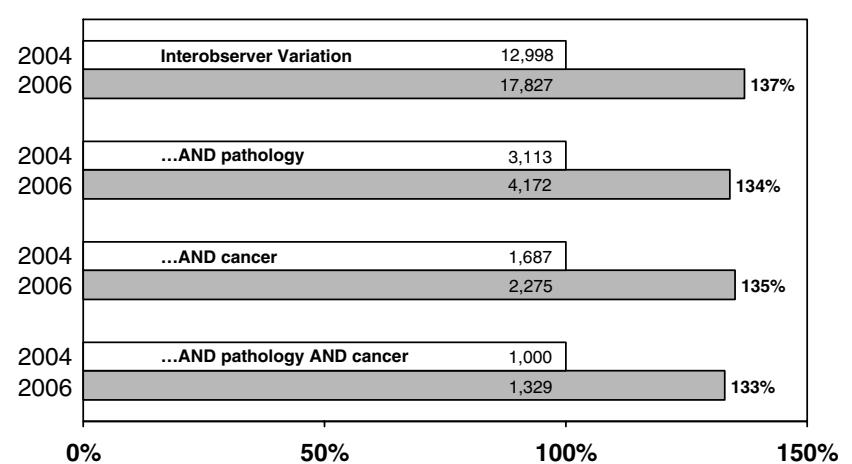

Figure 2 PubMed citations in four topic categories, as of September 18, 2004 (white bars) and October 29, 2006 (gray bars). PubMed

(www.pubmed.gov) is a service of the National Library of Medicine and the National Institutes of Health.

clinical management decisions based on a numerical 'score' from a morphological interpretation of biopsy tissue or an excised specimen, then the Pathologist is making the clinical treatment decision. This is based on the premise that the 'score' determines the treatment algorithm. The onus is very much on the Pathologist to know the treatment implications of their numerical scoring. Interestingly, it is precisely this arena where liver biopsy interpretation has been validated as an exercise in EBM. Peter Scheuer published in 1991 a critical opinion, stating that rigorous scoring of liver biopsies in viral hepatitis had to be changed, and providing a proposed scoring system for so doing. ${ }^{44}$ A rash of echoing papers followed (reviewed in 2). Within five years, Poynard concluded on the basis of metanalysis of randomized clinical trials (the peak of the 'EBM' pyramid) that rigorous semi-quantitative scoring systems for liver biopsies in viral hepatitis are indeed valid for clinical management decisions. ${ }^{45}$

But: a liver biopsy is not uniform. Interpretive judgment has to be used to 'score' the biopsy. Judgment can only be exercised on the basis of experience. So we are back to 'experience' underlying the 'evidence base' in anatomic pathology. Put differently, the Pathologist has remarkable power in an EBM setting, owing to the lower reproducibility of morphological evidence (as opposed to quantitative 'scientific' observation). Owing to the need for rigor and experience in the issuance of diagnostic reports, there is very definitely a role for 'eminence' in our field. Hence, no matter how 'evidence based' a clinical:pathologic paradigm for treatment, the Surgical Pathologist still has to interpret the histopathology. Judgment and experience remain regardless of how the objective criteria are to be used. Whether these issues apply across other anatomic pathology specialties (including cytopathology) will be left for others to examine.

The vagaries of obtaining rigorous pathology morphological interpretation are well documented elsewhere (as discussed in Marchevsky, ${ }^{25} \mathrm{Raab}^{39}$ ). Recent examples abound, ${ }^{34,46-56}$ regardless of whether the operative terms are 'interobserver variation' or outright 'error. ${ }^{57-59}$ We thus encounter a fundamental challenge in the use of morphological data in EBM. The evidence base in the literature must be integrated with personal experience and judgment in order to render a successful morphological interpretation of human tissue. ${ }^{25}$ Pathologists may have great difficulty in agreeing upon such interpretations and may be subject to 'error', particularly in those areas where rigor is needed most, such as the diagnosis of dysplasia. Nevertheless, such interpretations are inserted into algorithmic 'evidence based' paradigms for the treatment of patients. A most remarkable event then occurs: this process actually works! In the many subspecialty areas of anatomic pathology the rigorous efforts of Pathologists do indeed promote favorable outcomes in patient care. Beginning with cervical cytopathology, ${ }^{28}$ screening programs for the discovery of cancer at its earliest stages-with the interpretive expertise of anatomic pathologists prominently featured - constitute one of the best examples of the practice of evidence-based medicine over the past several decades. ${ }^{36}$ Ultimately, it is the integration of the pathologist's interpretation into the multidisciplinary management of the patient which promotes optimal patient care. ${ }^{60,67}$ I should also note that inclusion of the pathologist as contributing author on such publications is imperative.

Nevertheless, there are numerous examples in which practices in anatomic pathology are inadequately supported by evidence, ${ }^{35}$ and the rapidly increasing demand for molecular testing of tissue specimens can constitute a disconcerting departure from EBM if potential uses have not been adequately validated. ${ }^{37,61}$ It is essential that both anatomic pathology and Laboratory Medicine continue to strive for both the highest standards for practice, and for the rigorous data sets that justify (or refute) our practices. ${ }^{33,62,63}$

\section{THE ACADEMIC PRODUCTIVITY OF PATHOLOGY SCHOLARS}

Returning to the concept that pathology research is all things to all people, one could argue that 'pathology research' has no specific identity. The 'investigative pathologist' is hard to define, although it is reasonable to state that essentially all of the vocabulary and much of the intellectual foundation of modern medicine is derived from research by investigative pathologists' in the 19th and 20th centuries. ${ }^{64}$ In the first half of the 20th century, pathology played an extraordinary role in the advances of public health, with success in dealing with infectious diseases being the salient example. In the second half of the 20th century, 'investigative pathologists' drew ever increasingly upon the basic science laboratory to gain insights into human disease, with molecular and genetic medicine figuring ever more prominently. As a result, with the dawn of the 21st century, the research portfolio of academic pathology is encyclopedic. Each academic pathology department in turn must establish their optimal research portfolio and product, and define what their contribution to the expanse of medical knowledge should be.

To obtain insight into this issue, a sample of North American academic pathology departments were examined 
for their output of medical journal publications. Specifically, the six participating speakers at the summer 2006 meeting of the Association of Pathology Chairs (see Acknowledgement) gave permission for a $100 \%$ audit of their department's published papers for the calendar year 2005. Five of these departments were in the United States, one in Canada. The Tomson Science Citation Index ${ }^{\circledR}$ was searched for publications from these six departments for calendar year 2005. Published papers were classified according to whether they were supported by extramural funding (based on the Acknowledgement) or were 'unfunded' and clinical in nature. For the 'funded' papers, the department and institutional affiliation of the corresponding author (based on the Title Page) also were identified. Lastly, the journal of publication was classified as a 'pathology' journal, a 'top general' journal (specifically, J Am Med Assoc, J Clin Invest, J Exp Med, Nature, New Eng J Med, Proc Natl Acad Sci USA, Science), a 'basic science' journal (eg, J Biol Chem, J Immunol, J Virol), or a 'Disease/Organ' journal (eg, Gastroenterology, Circulation, Nephron, Brain, Diabetes).

There were a total of 922 papers published in calendar year 2005 from these six departments; of which 702 (74\%) were supported by extramural funds, and 220 (26\%) were 'unfunded' and clinical in nature (Figure 3). For the published funded research, 323 papers (35\% of the 922 total papers) had a member of the host Department of Pathology as corresponding author. On 184 papers (20\% of total), a 'pathology' faculty member was contributing author for a paper submitted from the same institution, and for 175 papers (19\% of total) the 'pathology' faculty member was a collaborator with a different institution. Two conclusions are drawn. First, funded faculty in these six departments of pathology make a major contribution to the academic productivity of each department, with collaborative work exceeding corresponding authorship. Collaborations are evenly split between the home institution and an outside institution. 'Funded' papers originating from the host

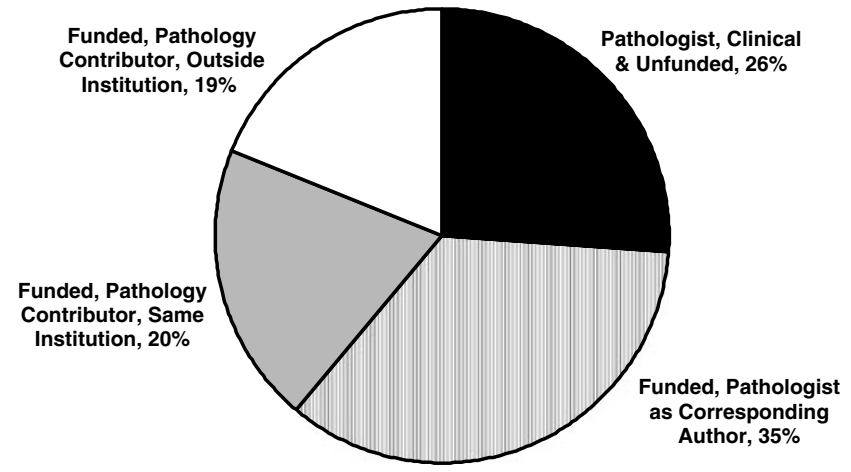

Figure 3 Classification of 2005 publications from six North American academic Departments of Pathology (five from the United States, one from Canada), according to funding status (per paper acknowledgement) and institutional affiliation of corresponding author. Data represent 992 publications. departments are still impressive in number, constituting 1/3 of the academic productivity of these departments. Based on 2004 data from the Association of American Medical Colleges (AAMC), $45 \%$ of academic Pathology faculty in the US are classified as 'clinical', and $55 \%$ as 'basic'. One might extrapolate that $55 \%$ of the faculty ('basic') produce $74 \%$ of the published papers, while $45 \%$ of the faculty ('clinical') produce $26 \%$ of the published papers.

This leads then to the second conclusion: clinical 'unfunded' faculty constitute $\frac{1}{4}$ of the academic productivity of these departments. This latter fact is neglected with risk, since the ability of unfunded clinical faculty to pursue scholarship may have a major impact on the overall productivity-and reputation-of a department. ${ }^{68}$

The question then arises of where these papers are published. Figure 4 shows the distribution of published papers in 'pathology' journals (12\%), 'top general' journals (4\%), 'basic science' journals (37\%), and 'disease/organ' journals (47\%). The favorite journals outside the 'pathology' field were J Immunol (53 papers; $6 \%$ of total); J Biol Chem (26 papers; $3 \%$ of total); and J Virol (16 papers; $2 \%$ of total) - all classified as 'basic science' journals. The 'disease/organ' journal distribution was very broad, with only Infection and Immunity (10 papers; $1 \%$ of total) and Diabetes (9 papers, $1 \%$ of total) gaining a plurality. In keeping with a 2005 Lab Invest editorial, ${ }^{65}$ it is clear that 'pathology' faculty seek a reading public largely outside the pathology literature. This supports the premise that defining the current identity of investigative pathology is somewhat difficult.

Among the 28 major 'pathology' journals, Table 1 lists the journal of publication for the 111 papers published therein. More detailed data for 20 journals are presented, with $A m \mathrm{~J}$ Clin Pathol, Am J Pathol, Am J Surg Pathol, Arch Pathol Lab

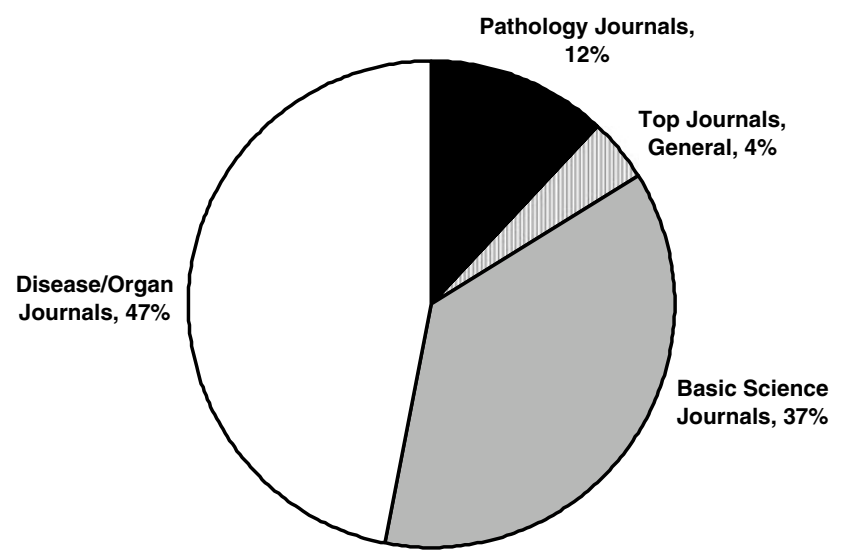

Figure 4 Classification of 2005 publications from six North American academic Departments of Pathology (five from the United States, one from Canada), according to journal. 'Pathology Journals' represent 28 pathology journals (see Table 1). 'Top Journals' refer to: J Am Med Assoc, J Clin Invest, J Exp Med, Nature, New Eng J Med, Proc Natl Acad Sci USA, and Science. 'Basic Science' journals are classified on the basis of scientific discipline; 'Disease/ Organ' journals are classified on the basis of clinical specialty or disease interest. Data represent 992 publications. 
Table 1 Classification of 2005 publications from six North American academic Departments of Pathology (five from the US, one from Canada), published in 28 pathology journals

\begin{tabular}{|c|c|c|c|c|c|}
\hline Journal & No. articles & No. 'funded' & No. 'clinical' & $\%$ Funded & $\%$ Clinical \\
\hline Acta Cytol & 4 & 1 & 3 & 25 & 75 \\
\hline Am J Pathol & 12 & 12 & 0 & 100 & 0 \\
\hline Am J Surg Pathol & 10 & 0 & 10 & 0 & 100 \\
\hline Arch Pathol Lab Med & 9 & 0 & 9 & 0 & 100 \\
\hline Clin Chem & 3 & 0 & 3 & 0 & 100 \\
\hline Diagn Cytopathol & 3 & 0 & 3 & 0 & 100 \\
\hline Diagn Molecular Pathol & 1 & 1 & 0 & 100 & 0 \\
\hline Exp Mol Pathol & 5 & 3 & 2 & 60 & 40 \\
\hline J Clin Pathol & 4 & 1 & 3 & 25 & 75 \\
\hline J Lab Clin Med & 1 & 1 & 0 & 100 & 0 \\
\hline J Mol Diag & 4 & 2 & 2 & 50 & 50 \\
\hline J Neuro Exp Neuropathol & 3 & 1 & 2 & 33 & 67 \\
\hline J Pathol & 0 & 0 & 0 & & \\
\hline Lab Invest & 8 & 7 & 1 & 88 & 13 \\
\hline Mod Pathol & 10 & 1 & 9 & 10 & 90 \\
\hline Total $(n=28)$ & 111 & 32 & 79 & 29 & 71 \\
\hline
\end{tabular}

Information is given on funding status (as declared in the paper acknowledgement) for 20 of the 28 journals available for review. Among the published papers from these six departments, only those published in Am J Pathol and Lab Invest were substantially funded from extramural sources.

Med, Mod Pathol, and Lab Invest having eight or more published papers from the 922 total. Inspection of these 111 papers revealed that 12 of the 12 papers published in $A m \mathrm{~J}$ Pathol were extramurally funded research, as were seven of the eight papers published in Lab Invest (the only 'unfunded' paper was the aforementioned Lab Invest editorial; 2). For the remaining 18 journals in Table 1, only 12 papers were extramurally funded, and 74 were 'unfunded' clinical scholarship. In this case, the 74 'unfunded' clinical papers in 'pathology' journals represent $30 \%$ of the 240 papers published by 'unfunded' clinical faculty. Besides this evidence that clinical 'pathology' faculty largely publish outside the 'pathology' literature, it is also true that the preponderance of 'pathology' journals cater to 'unfunded' clinical pathology faculty.

This exercise has not attempted to determine the impact (scientific or otherwise) of the published papers. However, Table 2 continues the exercise of Crawford and Tykocinski in $2005,{ }^{65}$ examining the distribution of 'pathology' papers among the eight top Impact Factor journals, the eight top 'disease/organ' journals (identified on the basis of the top journal for each clinical specialty), and the eight top pathology journals, with updated data for the first months of 2006. Table 3 places these three journal groups in perspective to all journals in the Thomson Science Citation Index ${ }^{\circledR}$ portfolio. For the past 3 years, over $95 \%$ of some 6000 journals have impact factors between 0.000 and 4.999. Only two of the 28 'pathology' journals (Am J Pathol, J Pathol) fall into the top 5\% of journals, with 2005 Impact Factors of 5.796 and 6.213, respectively. In aggregate, the Impact Factor of the eight top 'pathology' journals has not changed substantively since 1995, hovering around 3.6 (data not shown).

This exercise highlights the peculiar place of clinical scholarship in the practice of pathology. For the most part, original research in anatomic pathology is 'observational'. Nevertheless, such observations constitute bedrock data for the practice of EBM. This exercise also brings up the issue of the visibility of the clinical 'specialty' of pathology. Pathology 
Table 2 PubMed search for the term 'pathology' (delimited to 'human'), for the dates 1 January to 15 May 2005 and 1 January to 25 June 2006

\begin{tabular}{|c|c|c|c|c|c|c|c|}
\hline Journal & $\begin{array}{c}\text { Impact factor } \\
2006\end{array}$ & $\begin{array}{l}\text { Pathology articles } \\
1 / 1 / 05 \text { to } 5 / 15 / 05\end{array}$ & $\begin{array}{l}\text { Pathology articles } \\
1 / 1 / 06 \text { to } 6 / 25 / 06\end{array}$ & Sum 2005 & Sum 2006 & $\%^{\mathrm{a}} 2005$ & $\%^{\mathrm{b}} 2006$ \\
\hline Annu Rev Immunol & 47.400 & 0 & 2 & & & & \\
\hline New Engl J Med & 44.016 & 0 & 10 & & & & \\
\hline Science & 30.927 & 20 & 10 & & & & \\
\hline Nature & 29.273 & 40 & 7 & & & & \\
\hline Cell & 29.431 & 4 & 5 & & & & \\
\hline JAMA-J Am Med Assoc & 23.494 & 6 & 11 & & & & \\
\hline J Clin Invest & 15.053 & 66 & 31 & & & & \\
\hline$J$ Exp Med & 13.965 & 18 & 26 & 154 & 102 & 21 & 13 \\
\hline J Natl Cancer I & 15.171 & 36 & 11 & & & & \\
\hline Neuron & 14.304 & 4 & 10 & & & & \\
\hline Gastroenterology & 12.386 & 48 & 23 & & & & \\
\hline Circulation & 11.632 & 4 & 57 & & & & \\
\hline Mol Cell Proteomics & 9.876 & 1 & 11 & & & & \\
\hline Hepatology & 9.792 & 36 & 26 & & & & \\
\hline Brain & 7.535 & 48 & 76 & & & & \\
\hline J Am Soc Nephrol & 7.240 & 1 & 18 & 178 & 232 & 24 & 28 \\
\hline J Pathol & 6.213 & 82 & 78 & & & & \\
\hline Am J Pathol & 5.796 & 63 & 80 & & & & \\
\hline J Neuropath Exp Neur & 4.471 & 34 & 49 & & & & \\
\hline Am J Surg Pathol & 4.377 & 77 & 90 & & & & \\
\hline Brain Pathol & 4.041 & 27 & 24 & & & & \\
\hline Lab Invest & 3.859 & 25 & 29 & & & & \\
\hline Mod Pathol & 3.426 & 59 & 66 & 404 & 478 & 55 & 59 \\
\hline Hum Pathol & 2.550 & 38 & 62 & & & & \\
\hline
\end{tabular}

a Sum for group.

${ }^{b}$ Total articles for these 24 journals.

Eight journals each were selected for numeration in descending order for 2006 Impact Factor: the top eight general journals according to Impact Factor; the first eight journals encountered for any organ or disease category; and the top eight Pathology journals. Both absolute number of published articles with key word 'pathology', and percentage of total for these groupings are given. There is relative consistency for the 2 years (2005 and 2006). PubMed (www.pubmed.gov) is a service of the National Library of Medicine and the National Institutes of Health. Impact Factor is provided by Thomson Science Citation Index Inc. ${ }^{\circledR}$ (http:// portal.isiknowledge.com/portal.cgi).

is a small specialty relative to the major clinical specialties. It is therefore unlikely that there will be global visibility for our publications in 'pathology' journals, since they are directed at the specific practice of our own profession by said Pathologists. To the extent that our clinical scholarship is directed towards 'disease/organ' journals, our clinical colleagues will be able to appreciate the impact of our work on their practice of medicine. The fundamental challenge remains nevertheless: to publish the highest quality original scholarship, both to enhance our ability to provide outstanding patient care and, ultimately, to better understand human disease.

\section{CONCLUSION}

This perspective has attempted to demonstrate that anatomic pathology has a unique place in the practice of EBM. On the one hand, the knowledge base in this specialty is predominantly observational. Moreover, at this point in time, a high level of experience and judgment is required on the part of the contributing pathologists in order to generate rigorous data from which publications emanate. On the other hand, there is growing evidence that the data provided by practitioners of anatomic pathology is highly relevant and valuable to the practice of EBM in the clinical arena. Although there is 


\begin{abstract}
Table 3 Impact Factors for the approximately 6000 journals reported by Thomson Science Citation Index, Inc. ${ }^{\circledR}$ Journals are ranked by 5 -point range $(0.000-4.999 ; 5.000-9.999$, etc.), for the calendar years 2003, 2004, and 2005
\end{abstract}

\begin{tabular}{|c|c|c|c|c|c|c|}
\hline \multirow[t]{2}{*}{ Impact factor range } & \multicolumn{3}{|c|}{ Number of journals } & \multicolumn{3}{|c|}{$\%$} \\
\hline & 2003 & 2004 & 2005 & 2003 & 2004 & 2005 \\
\hline $50-55$ & 1 & 1 & 0 & 0.02 & 0.02 & 0.00 \\
\hline $45-50$ & 0 & 0 & 2 & 0.00 & 0.00 & 0.03 \\
\hline $40-45$ & 0 & 1 & 1 & 0.00 & 0.02 & 0.02 \\
\hline $35-40$ & 3 & 2 & 0 & 0.05 & 0.03 & 0.00 \\
\hline $30-35$ & 6 & 8 & 5 & 0.10 & 0.14 & 0.08 \\
\hline $25-30$ & 9 & 2 & 7 & 0.15 & 0.03 & 0.11 \\
\hline $20-25$ & 5 & 12 & 8 & 0.08 & 0.20 & 0.13 \\
\hline $15-20$ & 17 & 18 & 21 & 0.29 & 0.30 & 0.34 \\
\hline $10-15$ & 45 & 49 & 52 & 0.76 & 0.83 & 0.85 \\
\hline $5-10$ & 178 & 191 & 200 & 3.01 & 3.23 & 3.29 \\
\hline $0-5$ & 5643 & 5635 & 5792 & 95.53 & 95.20 & 95.14 \\
\hline
\end{tabular}

Only two 'Pathology' journals have had Impact Factors above 5.000 (Am J Pathol and J Pathol) during this interval.

substantial concern about the vagaries of 'error' and 'interobserver variation' in anatomic pathology, pathologists exhibit a commendable ability to practice their observational art with rigor, so as to effect optimal patient outcomes locally on a case-by-case basis, and to contribute valuable data to the broader context of EBM trials. It remains to be seen whether more quantitative technologies for anatomic pathology will improve upon our time-honored practices. It also remains to be seen whether evidence bases can be obtained for the ever increasing introduction of molecular technologies into the interpretation of tissue samples.

The additional message of this perspective is that the scholarship emanating from clinical faculty in academic Departments of Pathology is crucial to the advancement of EBM. Although the productivity of such faculty may be less than colleagues with protected 'research' time, it is precisely their scholarship which helps advance clinical science and, ultimately, the validation (or not) of therapeutic interventions for human disease. If Impact Factor is any reflection of readership, the publication of clinical scholarship in the 'pathology' journals may lead to lower visibility of such scholarship than might be obtained from publication in higher impact organ- or disease-based journals. A dilemma therefore arises, in regards to the visibility of our specialty and discipline in the broader context of medicine. Whether the 'pathology' journals in specific, and our specialty in general, can maintain scientific preeminence remains an important challenge. The ultimate goal remains: to understand human disease for the benefit of mankind.

\section{ACKNOWLEDGEMENTS}

Thanks are given to Catherine M Ketcham, PhD, Managing Editor for Laboratory Investigation, for her data and figure generation in support of this Editorial Perspective. Richard J Hausner, MD, provided valuable historical information on the 20th century foundations of the specialty of Pathology, drawing upon sources in Wagner ${ }^{66}$ and the web pages of the American Society for Clinical Pathology (www.ascp.org) and the College of American Pathologists (www.cap.org). Concepts presented in the first and second sections of this perspective were presented in part at the Florida Society of Pathologists 2006 annual meeting, in Orlando, FL on January 28, 2006, and at the United States and Canadian Academy of Pathologists 2006 annual meeting, in Atlanta, GA on February 12, 2006. Concepts presented in the third section of this perspective were presented in part at an Optical Imaging Workshop hosted by the National Cancer Institute, on September 25, 2006 in Bethesda, MD. Concepts presented in the fourth section of this manuscript ('academic productivity') were presented in part at the summer 2006 annual meeting of the Association of Pathology Chairs, in Colorado Springs, CO on July 14, 2006. Participating speakers at the last meeting who gave permission for a 100\% audit of 2005 published productivity of their departments were: James M Crawford, MD, PhD, Department of Pathology, Immunology and Laboratory Medicine, University of Florida College of Medicine, Gainesville, FL; Richard G Hegele, MD, PhD, Department of Pathology and Laboratory Medicine, University of British Columbia, Vancouver, Canada; Jay L Hess, MD, PhD, Department of Pathology, University of Michigan, Ann Arbor, Ml; John B Lowe, MD, Department of Pathology, Case Western Reserve University School of Medicine, Cleveland U54 CA105480, OH; Tristram G Parslow, MD, PhD, Department of Pathology and Laboratory Medicine, Emory University Hospital, Atlanta, GA; and Kenneth L Rock, MD, Department of Pathology, University of Massachusetts School of Medicine, Worcester, MA. This work was supported in part by a grant from The National Cancer Institute, U54 CA105480, in support of the 'Network for Translational Research in Optical Imaging' (NTROI).

\section{NOTE ADDED IN PROOF}

A recent publication documents that half of all renal practice evidence published between 1961-2005 also was published in non-renal journals (Barg AX, lansavichius AV, Kastner M, et al. Kidney Int 2006;70:1995-2005). The issue of journal-of-publication is not limited to pathology.

1. MacDonogh G. The Last Kaiser: The Life of Wilhelm II. St. Martin's Griffin: New York, NY, 2000, pp 192-213.

2. Crawford JM. Evidence-based interpretation of liver biopsies. Lab Invest 2006;86:326-334.

3. Foucar E, Wick MR. An observational examination of the literature in diagnostic anatomic pathology. Semin Diagn Pathol 2005;22: 126-138.

4. Foucar E. Classification of error in anatomic pathology: a proposal for an evidence-based standard. Semin Diagn Pathol 2005;22: 139-146.

5. Eddy DM. Evidence-based medicine: a unified approach. Health Affairs 2005;24:9-17.

6. Wennberg JE, Gittelsohn A. Small area variations in health care delivery. Science 1973;82:1102-1108.

7. Chassin MR, Kosekoff J, Solomon DH, et al. How coronary angiography is used: clinical determinants of appropriateness. J Am Med Assoc 1987:258:2543-2547.

8. Committee for Evaluating Medical Technologies in Clinical Use. The 15 per cent figure comes from an Institute of Medicine study, which cites the Congressional Office of Technology Assessment. Assessing Medical Technologies. National Academics Press: Washington, 1985, p 5.

9. Eddy DM. Variations in physician practice: the role of uncertainty. Health Affairs 1984;3:74-89.

10. Eddy DM. Practice policies: where do they come from? J Am Med Assoc 1990;263:1265, 1269, 1272, 1275.

11. Akobeng AK. Understanding randomised controlled trials. Arch Dis Child 2005;90:840-844. 
12. Stengle J. Review casts doubt on soy's benefits. The Seattle Times 23 January 2006; Tanner L. Fish oil doesn't cut cancer risk, review finds. Seatlle Post-Intelligencer 25 January 2006.

13. Begley $\mathrm{S}$. New journals bet negative results save time, money. Wall Street Journal 15 September 2006.

14. Mendelson D, Carino TV. Evidence-based medicine in the United States-de rigueur or dream deferred? Health Affairs 2005;24: 133-136.

15. Pacy J. Evidence-based medicine and the search for a science of clinical care. Social Health Illness 2006;28:122-123.

16. Sackett DL, Rosenberg WMC, Gray JAM, et al. Evidence based medicine: what it is and what it isn't. Br Med J 1996;312:71-72.

17. Greenhalgh T. Narrative based medicine in an evidence-based world. Br Med J 1999;318:323-325.

18. Valenstein PN, Raab SS, Walsh MK. Identification errors involving clinical laboratories. A College of American Pathologists Q-Probes study of patient and specimen identification errors at 120 institutions. Arch Pathol Lab Med 2006;130:1106-1113.

19. Zarbo RJ, Jones BA, Friedberg RC, et al. Q-Tracks. A College of American Pathologists program of continuous laboratory monitoring and longitudinal performance tracking. Arch Pathol Lab Med 2002;126:1036-1044.

20. Hollensead SC, Lockwood WB, Elin RJ. Errors in pathology and laboratory medicine: consequences and prevention. J Surg Oncol 2004;88:161-181.

21. Kalra J. Medical errors: an introduction to concepts. Clin Biochem 2004;37:1043-1051.

22. Kalra J. Medical errors: impact on clinical laboratories and other critical areas. Clin Biochem 2004;37:1052-1062.

23. Price $C$. Evidence-based laboratory medicine: supporting decisionmaking. Clin Chem 2000;46:1041-1050.

24. McQueen MJ. Overview of evidence-based medicine: challenges for evidence-based laboratory medicine. Clin Chem 2001;47:1536-1546.

25. Marchevsky AM. Evidence-based medicine in pathology: an introduction. Semin Diagn Pathol 2005;22:105-115.

26. Trenti T. Evidence-based laboratory medicine as a tool for continuous professional improvement. Clin Chem Acta 2003;333:155-167.

27. Baker PB, Zarbo RJ, Howanitz PH. Quality assurance of autopsy face sheet reporting, final autopsy report turnaround time, and autopsy rates: a College of American Pathologists Q-Probes study of 10,003 autopsies from 418 institutions. Arch Pathol Lab Med 1996;120: 1003-1008.

28. Wright Jr TC, Cox JT, Massad LS, et al. 2001 Consensus guidelines for the management of women with cervical cytological abnormalities. J Am Med Assoc 2002;287:2120-2129.

29. Sirota RL. The Institute of Medicine's report on medical error: implications for pathology. Arch Pathol Lab Med 2000;124: 1674-1678.

30. Marchevsky AM, Wick MR. Evidence-based medicine, medical decision analysis, and pathology. Hum Pathol 2004;35:1179-1188.

31. Zarbo RJ. Monitoring anatomic pathology practice through quality measures. Clin Lab Med 1999;19:713-742.

32. Zarbo RJ, Meier FA, Raab SS. Error detection in anatomic pathology. Arch Pathol Lab Med 2005;129:1237-1245.

33. Raab SS, Grzybicki DM, Zarbo RJ, et al. Anatomic pathology databases and patient safety. Arch Pathol Lab Med 2005;129:1246-1251.

34. Raab SS, Grzybicki DM, Janosky JE, et al. Clinical impact and frequency of anatomic pathology errors in cancer diagnoses. Cancer 2005;104:2205-2213.

35. Wick MR, Bourne D, Patterson JW, et al. Evidence-based principleas and practices in pathology: selected problem areas. Semin Diagn Pathol 2005;22:116-125.

36. Foucar E. Diagnostic precision and accuracy in interpretation of specimens from cancer screening programs. Semin Diagn Pathol 2005;22:147-155.

37. Marchevsky AM. The application of special technologies in diagnostic anatomic pathology: is it consistent with the principles of evidencebased medicine? Semin Diagn Pathol 2005;22:156-166.

38. Wick MR, Foucar E. Evidence-based medicine and tort law. Semin Diagn Pathol 2005;22:167-176.

39. Raab SS. Variability of practice in anatomic pathology and its effect on patient outcomes. Semin Diagn Pathol 2005;22:177-185.
40. Corley $\mathrm{DE}$, Kirtland $\mathrm{SH}$, Winterbauer $\mathrm{RH}$, et al. Reproducibility of the histologic diagnosis of pneumonia among a panel of four pathologists: analysis of a gold standard. Chest 1997;112:458-465.

41. Rorke LB. Pathologic diagnosis as the gold standard. Cancer 1997;79:665-667.

42. Rushing $\mathrm{L}$, Joste $\mathrm{N}$. The surgical pathology report: Standardizing the 'Gold Standard'. J Surg Oncol 1997;65:1-2.

43. Wells AU. Histopathologic diagnosis in diffuse lung disease: an ailing gold standard. Am J Resp Crit Care Med 2004;170:828-829.

44. Scheuer PJ. Classification of chronic viral hepatitis: a need for reassessment. J Hepatol 1991;13:372-374.

45. Poynard T, Leroy V, Cohard M, et al. Meta-analysis of interferon randomized trials in the treatment of viral hepatitis C: effects of dose and duration. Hepatology 1996;24:778-789.

46. Apple SK. Variability in gross and microscopic pathology reporting in excisional biopsies of breast cancer tissue. Breast J 2006;12:145-149.

47. Coffin CM, Spilker $\mathrm{K}$, Zhou H, et al. Frozen section diagnosis in pediatric surgical pathology: a decade's experience in a children's hospital. Arch Pathol Lab Med 2005;129:1619-1625.

48. Coffin CM. Pediatric surgical pathology: pitfalls and strategies for error prevention. Arch Pathol Lab Med 2006;130:610-612.

49. Cooper K. Errors and error rates in surgical pathology: an Association of Directors of Anatomic and Surgical Pathology survey. Arch Pathol Lab Med 2006;130:607-609.

50. Grzybicki DM, Turcsanyi B, Becich MJ, et al. Database construction for improving patient safety by examining pathology errors. Am J Clin Pathol 2005;124:500-509.

51. Renshaw AA. Measuring and reporting errors in surgical pathology. Am J Clin Pathol 2001;115:338-341.

52. Renshaw AA, Pinnar NE, Jiroutek MR, et al. Blinded review as a method for quality improvement in surgical pathology. Arch Pathol Lab Med 2002;126:961-963.

53. Renshaw AA, Cartagena N, Granter SR, et al. Agreement and error rates using blinded review to evaluate surgical pathology of biopsy material. Am J Clin Pathol 2003;119:797-800.

54. Renshaw AA, Young ML, Jiroutek MR. How many cases need to be reviewed to compare performance in surgical pathology? Am J Clin Pathol 2003;119:388-391.

55. Renshaw AA, Gould EW. Measuring the value of review of pathology material by a second pathologist. Am J Clin Pathol 2006;125:737-739.

56. Renshaw AA. Comparing methods to measure error in gynecologic cytology and surgical pathology. Arch Pathol Lab Med 2006;130: 626-629.

57. Sirota RL. Error and error reduction in pathology. Arch Pathol Lab Med 2005; 129:1228-1233.

58. Sirota RL. Defining error in anatomic pathology. Arch Pathol Lab Med 2006;130:604-606.

59. Nakhleh RE. Error reduction in surgical pathology. Arch Pathol Lab Med 2006;130:630-632.

60. Flaherty KR, King TE, Raghu G, et al. Idiopathic interstitial pneumonia: what is the effect of a multidisciplinary approach to diagnosis? Am J Resp Crit Care Med 2004;170:904-910.

61. Altman DG, Riley RD. Primer: an evidence-based approach to prognostic markers. Nat Clin Pract Oncol 2005;2:466-472.

62. Raab SS. Improving patient safety through quality assurance. Arch Pathol Lab Med 2006;130:633-637.

63. Association of Directors of Anatomic and Surgical Pathology. Recommendations for quality assurance and improvement in surgical and autopsy pathology. Human Pathol 2006;37:985-988.

64. Korn D. Contribution of the Human Tissue Archive to the advancement of medical knowledge and the public health. A report to the National Bioethics Advisory Committee. US Government Printing Office: Bethesda, MD, January 1, 1998.

65. Crawford JM, Tykocinski M. Pathology as the enabler of human research. Lab Invest 2005;85:1058-1064.

66. Wagner RL (ed). In Pursuit of Excellence: The College of American pathologists, 1946-1996. CAP Press: Northfield, IL, 1997.

67. Walker PD, Cavello T, Bonsib SM. Practice guidelines for the renal biopsy. Mod Pathol 2004;17:1555-1563.

68. Borkowski A, Berman JJ, Moore GW. Research by pathologists not funded by external grant agencies: a success story. Mod Pathol 1992:5:577-579. 